\title{
PROFILE OF LUNG CANCER PATIENTS AT TERTIARY CARE HOSPITAL OF NORTH INDIA
}

\author{
Anand Kumar1, Luvkush², Sanjay Verma³, Prashant Yadav 4 , Avadhesh Kumar 5 , Anurag Shukla 6 \\ ${ }^{1}$ Associate Professor, Department of Tuberculosis and Respiratory Diseases, GSVM Medical College, Kanpur. \\ ${ }^{2}$ Senior Resident, Department of Pulmonary Medicine, MAMC, New Delhi. \\ ${ }^{3}$ Associate Professor, Department of Tuberculosis and Respiratory Diseases, GSVM Medical College, Kanpur. \\ ${ }^{4}$ Senior Resident, Department of Pulmonary Medicine, UP RIMS, Saifai Etawah, U. P. \\ ${ }^{5}$ Assitant Professor, Department of Tuberculosis and Respiratory Diseases, GSVM Medical College, Kanpur. \\ ${ }^{6}$ Senior Resident, Department of Tuberculosis and Respiratory Diseases, GSVM Medical College, Kanpur.
}

\section{ABSTRACT}

\section{BACKGROUND}

Cancer is a leading cause of death worldwide and lung cancer is the most common cancer in men. The aim of this study was to study the profile of patients of lung or pleural tumour and their cyto-histopathological type reporting to Department of Respiratory Diseases of GSVM Medical College, Kanpur.

\section{MATERIALS AND METHODS}

A total of 147 patients were included in the study. Patients were subjected to detailed history and general and systemic examination. Radiological investigations were reviewed and repeated as per requirement. Computed tomography/ Ultrasonography guided lung biopsy was done in peripherally located lesion and bronchoscopy guided procedures were performed in centrally located lesions. All histological and cytological results were noted.

\section{RESULTS}

In this study, 65 patients (44.20\%) were diagnosed as squamous cell carcinoma and 58 patients (39.4\%) were as adenocarcinoma. 14 patients $(9.5 \%)$ as small cell carcinoma, 4 patients $(2.74 \%)$ as large cell carcinoma, 3 patients $(2.04 \%)$ as adenosquamous cell carcinoma and 3 patients $(2.04 \%)$ as pleural mesothelioma. There was higher prevalence of squamous cell carcinoma among male patients (45.2\%) as compared to adenocarcinoma (40\%), while this ratio was reversed in case of female patients (adenocarcinoma $46.8 \%$ and squamous cell carcinoma $31.2 \%)$. There was higher incidence of small cell carcinoma in females (21.8\%) as compared to males $(6 \%)$.

\section{CONCLUSION}

Squamous cell carcinoma is still the most common histological type of lung cancer in male. There was relatively increased frequency of adenocarcinoma in our study as compared to other studies from India.

\section{KEYWORDS}

Lung Cancer, Cyto-Histopathological Profile.

HOW TO CITE THIS ARTICLE: Kumar A, Luvkush, Verma S, et al. Profile of lung cancer patients at tertiary care hospital of North India. J. Evolution Med. Dent. Sci. 2017;6(60):4403-4406, DOI: 10.14260/Jemds/2017/952

\section{BACKGROUND \\ Cancer is a leading cause of death worldwide. It accounted for} 7.4 million deaths (around 13\% of all deaths) in 2004. Lung cancer has been the most common cancer in the world for several decades, and by 2008 there were an estimated 1.61 million new cases representing $12.7 \%$ of all new cancers. Lung cancer is the most common cancer in men worldwide and though incidence rates is lower in females still is now the fourth most frequent cancer of women and second most common cause of death from cancer in them (GLOBOCAN 2008 cancer fact sheet).[1]

Incidence rates are reportedly rising in newly industrialised and developing countries like China and India.

Financial or Other, Competing Interest: None.

Submission 07-06-2017, Peer Review 15-07-2017,

Acceptance 21-07-2017, Published 27-07-2017.

Corresponding Author:

Dr. Anand Kumar,

Associate Professor,

Department of Tuberculosis and Respiratory

Diseases, GSVM Medical College,

Kanpur.

E-mail: anandalka72@gmail.com

DOI: $10.14260 /$ jemds $/ 2017 / 952$

(c) $(7)$
The incidence of lung cancer is strongly correlated with cigarette smoking with about $90 \%$ of lung cancers arising as a result of tobacco use. The risk of lung cancer increases with the number of cigarettes and duration of smoking. Passive smoking, environmental pollution from vehicles, industry and power plants and exposure to asbestos is also an established risk factor for the development of lung cancer and mesothelioma.[2] The fact that not all smokers eventually develop lung cancer suggests that other factors such as individual genetic susceptibility may play a role in the causation of lung cancer.

Diagnosis of lung cancer is usually done by clinical examination, radiological investigation and histopathological diagnosis is established by bronchoscopy, Fine Needle aspiration cytology or biopsy, thoracocentesis and Sputum cytology. The present study has tried to observe clinicoepidemiological features of patient of the lung and plural tumours presenting to Department of Tuberculosis and Respiratory Diseases, GSVM Medical College, Kanpur, (UP) which will be helpful in planning of hospital care of lung and plural tumours of patients and public health measure to be taken and strengthening the role of early detection of lung cancer. 


\section{MATERIALS AND METHODS}

This was a prospective descriptive study conducted from January 2011 to January 2013 in Department of Tuberculosis and Respiratory Diseases, GSVM Medical College, Kanpur. Any patients presenting with clinical feature suspicious of lung cancer was included in the study. A detailed "information data sheet" regarding patient's age, sex, area of living, religion, occupation, exposure to environmental pollution or passive smoking, previous such illness or any other chronic illness, any medication or previous surgery was prepared. A family history of cancer was also noted.

Smoking history was taken in detail in the form of type of smoking- bidi or cigarette, age of start of smoking, duration of smoking, number of pack years, if left then duration of smoking left. Patients were subjected to detail general and systemic examination with special attention on symptoms related to paraneoplastic syndromes. Radiological investigations were reviewed and repeated as per requirement for better localisation of the pathology and anatomical classification of the diseases done accordingly. CT/USG guided lung biopsy was done in peripherally located lesion and bronchoscopy guided procedures were performed in centrally located lesions. Bronchoscopic finding was noted accordingly, site of lesion and type of lesion, all histological and cytological results were noted in the proforma. However, tumour markers and immunohistochemistry was not done in any of the patients. Histological typing was based on WHO classification of lung tumours, staging was done according to $6^{\text {th }}$ edition of AJCC TNM staging system.

\section{RESULTS \\ Demographics}

A total of 182 patients were enrolled for the study; 18 patients did not turn up for the investigation procedures and histopathological diagnosis could not be established in 10 patients; 5 patients turned out to be case of tuberculosis and 2 patients died during the workup for the diagnosis in the hospital. So 147 patients were included in the study for the analysis. There were 115 male patients and 32 female patients. Male-to-female ratio was 3.59: 1. Patients were from 40 to more than 80 years of age; however, maximum number of patients were from 50 to 70 years of age comprising a total of $71.57 \%$. Mean age was 60.25 years, (Male- 59.5 years and Females- 63.00 years). Maximum number of patients belonged to rural area comprising of $65 \%$ of the sample size and rest from urban area. (Table 1) 53\% patients were either farmers or agricultural labourers and $78 \%$ of the patients were of lower or lower middle class of socioeconomic status. Among patients of urban area, $40 \%$ patients were either industrial labourers or driver by occupation having history of exposure to environmental pollution. All the female were housewives and all of them had history of biomass fuel exposure.

\section{Smoking Habit}

In this study, 64.94\% (94) patients were smokers/exsmokers and $36.05 \%$ (53) were non-smokers. Among the smokers, bidi smokers were $75.39 \%$ followed by cigarette smokers $18.46 \%$. And $6.15 \%$ patients were having other smoking history like hukkah, chilam and ganja. Most of the patients started smoking in the age of 15 to 20 (89\%) (Table 2).
Mean duration of smoking was 27.2 years. However, minimum duration of smoking was $10 \mathrm{yrs}$. and maximum was 44 yrs. According to smoking index, maximum patients were having $(84.62 \%)$ smoking index $>300$. All the patients left smoking only after having some symptoms and sign of the diseases. Among the female patients only one had history of smoking, while $84.37 \%$ had history of biomass fuel exposure.

\section{Clinical Presentation and Radiological Presentations}

In this study, apart from classical respiratory symptoms of cough, chest pain and breathlessness $(83,76 \%$ and $63 \%$ respectively), $32 \%$ patients presented with haemoptysis and $19 \%$ patients presented with symptoms suggestive of compression of adjacent organs like facial swelling and dysphagia; $52.94 \%$ patients had one or other peripheral lymphadenopathy and $12 \%$ patients were having paraneoplastic syndrome like Horner syndrome, neuro/myopathy and dyselectrolytaemia. Among the comorbid illness, COPD was present in $12 \%$ of patients and only $5 \%$ patients presented with Diabetes mellitus. There were $8 \%$ of patients who have history of treatment for tuberculosis in the past.

On radiological review, patients presented with multiple radiological feature. Apart from space occupying lesion in 109 patients $(74.15 \%)$ on X-ray chest, 29 patients $(19.73 \%)$ presented with pleural effusion only, $9(6.12 \%)$ patients presented with mediastinal widening/parahilar mass. Among patients with space occupying lesions, $49 \%$ had associated pleural effusion and $25.15 \%$ had associated collapse or consolidation (Table 3). Among the patients presenting with pleural effusion, there were 10 having B/L pleural effusion. Contrast Enhanced Computed Tomography (CECT) was done in 138 patients and among them all except 9 were suggestive of space occupying lesions along with other features. Among these 9 patients 3 presented with pleural nodule and B/L pleural effusion, one with pleural effusion only and 6 patients with consolidation/collapse of lobe.

\section{Histological Presentation}

In this study, 65 patients (44.20\%) were diagnosed as squamous cell carcinoma and 58 patients (39.4\%) were diagnosed as adenocarcinoma; 14 patients (9.5\%) as small cell carcinoma, 4 patients $(2.74 \%)$ as large cell carcinoma, 3 patients $(2.04 \%)$ as adenosquamous cell carcinoma and 3 patients $(2.04 \%)$ as pleural mesothelioma (Table 4$)$. There was slightly higher prevalence of squamous cell carcinoma among male patients $(45.2 \%)$ as compared to adenocarcinoma (40\%), while this ratio was reversed in case of female patients where adenocarcinoma was $46.8 \%$ as compared to squamous cell carcinoma of $31.2 \%$. There was higher incidence of small cell carcinoma in females $(21.8 \%)$ as compared to males (6\%).

We also looked into the correlation between smoking and its association. It was found that squamous cell carcinoma (60\%) was predominant type among smokers, while adenocarcinoma was more seen in non-smokers (83\%). ODDS ratio for squamous cell carcinoma to adenocarcinoma in smoker was 9: 1 . While ODDS ratio for adenocarcinoma to squamous cell carcinoma among non-smoker was $2.8: 1 ; 80 \%$ patients of small cell carcinoma were smokers and all patients of large cell carcinoma, adenosquamous cell 
carcinoma and pleural mesothelioma were having smoking history.

Bidi smoking was more commonly associated with squamous cell carcinoma (67.35\%) than cigarette smoking (41.67\%).

Most of the patients of non-small cell carcinoma were in stage III (46.67\%) and IV (47.78\%) of carcinoma and only $6 \%$ cases presented in stage I and II. All 10 patients of small cell lung cancer were in extensive stage of lung cancer and two patients of pleural mesothelioma were in IV stage of disease.

\begin{tabular}{|c|c|c|c|c|}
\hline \multirow{2}{*}{ Age Group } & \multicolumn{2}{|c|}{ M } & \multicolumn{2}{c|}{ F } \\
\cline { 2 - 5 } & Rural & Urban & Rural & Urban \\
\hline < 40 yrs. & 1 & 0 & 0 & 1 \\
\hline $41-50$ yrs. & 10 & 3 & 0 & 2 \\
\hline $51-60$ yrs. & 27 & 13 & 6 & 5 \\
\hline $61-70$ yrs. & 27 & 13 & 7 & 6 \\
\hline $71-80$ yrs. & 12 & 5 & 2 & 2 \\
\hline$>80$ yrs. & 3 & 1 & 0 & 1 \\
\hline Total & \multicolumn{2}{|c|}{115 (78.2\%) } & \multicolumn{2}{c|}{$32(21.7 \%)$} \\
\hline
\end{tabular}

\begin{tabular}{|c|c|c|c|c|c|}
\hline & \multicolumn{3}{|c|}{ Smoker } & \multirow{2}{*}{$\begin{array}{c}\text { Non- } \\
\text { Smoker }\end{array}$} & \multirow{2}{*}{$\begin{array}{c}\text { Biomass } \\
\text { Fuel }\end{array}$} \\
\hline & Bidi & Cigarette & Others & & \\
\hline Male & 70 & 17 & 6 & 22 & \\
\hline Female & 1 & 0 & 0 & 31 & $27(84.37 \%)$ \\
\hline Total & \multicolumn{3}{|c|}{$94(64.94 \%)$} & \multicolumn{2}{|c|}{$53(36.05 \%)$} \\
\hline \multicolumn{6}{|c|}{ Table 2. Smoking Habit of the Patients } \\
\hline
\end{tabular}

\begin{tabular}{|c|c|c|}
\hline Sl. No. & $\begin{array}{c}\text { Radiological Presentation } \\
\text { on Chest X-Ray }\end{array}$ & $\begin{array}{c}\text { Number } \\
\text { (Percentage) }\end{array}$ \\
\hline 1. & Space Occupying Lesion & $109(74.15 \%)$ \\
\hline & a. $\quad$ With Pleural Effusion & $72(49.00 \%)$ \\
\hline & b. With Collapse/ Consolidation & $37(25.15 \%)$ \\
\hline 2. & Pleural Effusion Only & $29(19.73 \%)$ \\
\hline 3. & $\begin{array}{c}\text { Mediastinal Widening/ } \\
\text { Parahilar Mass }\end{array}$ & $9(6.12 \%)$ \\
\hline \multicolumn{3}{|c|}{ Table 3. X-Ray Presentation of Lung Cancer } \\
\hline
\end{tabular}

\begin{tabular}{|c|c|c|}
\hline Sl. No. & Histology & $\begin{array}{c}\text { Percentage } \\
\text { Total= 147 }\end{array}$ \\
\hline 1. & Squamous Cell Carcinoma & $65(44.20 \%)$ \\
\hline 2. & Adenocarcinoma & $58(39.4 \%)$ \\
\hline 3. & Small Cell Carcinoma & $14(9.5 \%)$ \\
\hline 4. & Large Cell Carcinoma & $4(2.74 \%)$ \\
\hline 5. & Adenosquamous Cell Carcinoma & $3(2.04 \%)$ \\
\hline 6. & Pleural Mesothelioma & $3(2.04 \%)$ \\
\hline \multicolumn{2}{|c|}{ Table 4. Histological Presentation of Lung Cancer } \\
\hline
\end{tabular}

\section{DISCUSSION}

This was an epidemiological study planned to find out the demographic and histological pattern of lung cancer patients. Average age of our patients was 60.25 years, although patient's age ranged from 40 to 70 yrs. only $9.8 \%$ patients were between 40 to 50 yrs. Peak year of incidence was between 50 - 70 yrs. comprising of around $72 \%$, which is quite similar to study by Gupta et al. Average age of bronchogenic carcinoma patients in our study was 60.25 yrs. Ochsner and Bakey reported that in $13.6 \%$ of 4307 collected cases the age was 20 - 39 years ${ }^{[3]}$; however, in recent studies conducted from India only $2 \%-3 \%$ patients were of age less than 40 yrs. Jindal et al[ ${ }^{[4]}$ found that $14.6 \%$ of the patients being aged less than 41 years and Day et al found that $9.4 \%$ patients were $\leq 40$ years of age.[5]
Most of our patients (65\%) belonged to rural area. This may be because most of the patients in our hospital comes from rural background and this may be just a reflection to the patient's profile of the hospital. However, this may have another implication that number of patients of lung cancer in rural population is also high.

Similar to other previous studies, male-to-female ratio in our study is high (3.59: 1), which is similar to the studies of $1970[6,7]$ but is far lesser to the recent Indian studies.[8,9] Higher prevalence in male is explained by smoking habit, high exposure to atmospheric pollution in outdoor activities in comparison to females but lower sex ratio in our study might be due to increasing incidence of lung cancer in women because of exposure to biomass fuel or other precipitating factors as none of our female patients were smokers. Smoker to non-smoker ratio was high in our study, but is lower to previous Indian studies showing high co-relation between smoking and lung cancer. Smoking correlation has been seen in $67.2 \%$ to as high as $90 \%$ from different Indian studies.[10,11,12] This signifies that incidence of lung cancer is increasing in non-smokers also. The development of lung cancer in non-smokers is explained by certain environmental and occupational exposures. Smoke from biomass combustion had got significant amount of carcinogens. It was possible that domestic cooking might be playing some role in causation of lung cancer in this country in comparison to increasing smoking in Western women. Behera and Balamugesh studied indoor air pollution as a risk factor for lung cancer in women and concluded that biomass fuel exposure is a principal risk factor in the causation of lung cancer among women in addition of exposure to tobacco smoke.[13]

Although $75.38 \%$ of our cases were bidi smokers, this is because of higher prevalence of bidi smokers in rural population. A strong association of lung cancer and smoking had been reported, but there was no suggestion that bidi smokers had higher prevalence of lung cancer as compared to cigarette smokers.[14] The high risk of bronchogenic carcinoma had a parallelism with an increasing smoking index. In our study, $84.62 \%$ of smoking patients were having smoking index of $>300$.

Smoking was also associated with histological typing of lung cancer; it was commonly associated with Squamous cell carcinoma, while larger number of non-smokers had adenocarcinoma which were consistent with finding of Lee et al and Shimizu et al who found smoking was responsible for $90 \%$ of squamous cell carcinoma in both men and women.[15,16,17]

Radiological presentation varied in the patients, but most of the patients presented late to our centre and mass lesion was the most common finding followed by pleural effusion, collapse and consolidation, mediastinal widening, rib erosion and chest wall involvement was not so frequent in our study. In earlier studies like Dull et al needle aspiration biopsies found to be having sensitivity for diagnosing pulmonary carcinoma was $79 \%$, while the specificity was $100 \%,[18]$ but over the years bronchoscopy and bronchoscopic guided procedure had took over and were considered as the procedure of choice for the diagnosis of lung cancer because of multiplicity of the specimens from a single invasive procedure. Gupta et al, Khan et al and Gaur et al.[19,20,21]

We used different diagnostic procedures to confirm the diagnosis. Preferred procedure was selected depending upon 
the site of lesion and ease of the procedure with least procedure related complication expectation. Pleural fluid cytology was diagnostic in almost $50 \%$ of the cases where pleural fluid for cytology was sent, followed by FNAC of lymph node (38 patients), FNAC of lung (32 patients), BAL fluid cytology (30 patients), bronchial brush smear (25 patients), bronchial biopsy (24 patients) and pleural biopsy (2 patients).

Histologically, number of patients of squamous cell carcinoma and adenocarcinoma was nearly equal in our study, 65 and 58 respectively, which is slightly different from other Indian studies where squamous cell carcinomas were predominant form, Gupta et al and Naseem et al[22] and Sheikh et al, while data from other countries suggested adenocarcinoma to be predominant type of lung cancer like in Taiwan, Perng et al. In Mexico city, Medina et al and Lam et al from Hong Kong reported adenocarcinoma to be most common type.[23,24]

The relatively increased frequency of adenocarcinoma in our study as compared to other studies from India was probably due to higher proportion of non-smokers.

In our study, majority of the patients of non-small cell carcinoma were in stage III (46.67\%) and IV (47.78\%) and only $5 \%$ to $6 \%$ cases were in I and II stage. All cases of small cell lung cancer and pleural mesothelioma were in advanced stage of lung cancer. This finding is consistent with many studies from India as well as abroad. Kumar et al and Alamoudi et al, Medina et al, Willcox et al also found in their study that majority of cases were diagnosed in the later stages of diseases (71.8\%).[13]

\section{CONCLUSION}

Squamous cell carcinoma is still the most common histological type of lung cancer in male. The relatively increased frequency of adenocarcinoma in our study as compared to other studies from India was probably due to higher proportion of non-smokers. Another aspect of our study, in which we found that majority of lung cancer was misdiagnosed as tuberculosis and treated with AntiTubercular Treatment (ATT), thereby causing delayed diagnosis. This emphasised the need for more effective method for early detection of lung cancer among general population.

\section{REFERENCES}

[1] Globocon cancer fact sheet. globocan.iarc.fr 2008.

[2] Smith GD. Smoking and lung cancer: causality, cornfield and an early observational meta-analysis. Int J Epidemiol 2009;38(5):1169-71.

[3] Ochsner A, De Bakey M. Carcinoma of the lung. Arch Surg 1941;42(2):209-58.

[4] Jindal SK, Malik SK, Dhand R, et al. Bronchogenic carcinoma in Northern Indian. Thorax 1982;37(5):343-7.

[5] Dey A, Biswas D, Saha SK, et al. Comparison study of clinicoradiological profile of primary lung cancer cases: an Eastern India experience. Indian J Cancer 2012;49(1):89-95.

[6] Beamis JF, Stein A, Andrews JL. Changing epidemiology of lung cancer. Increasing incidence in women. Medical Clinics of North America 1975;59(2):315-25.
[7] Menon MA, Saw HS. Lung cancer in Malaysia. Thorax 1979;34(2):269-73.

[8] Koul PA, Kaul SK, Sheikh MM, et al. Lung cancer in Kashmir valley. Lung India 2010;27(3):131-7.

[9] Sheema S, Azra S, Aijaz A, et al. Histological pattern of primary malignant lung tumours diagnosed in a tertiary care hospital: 10 year study. Asian Pacific J Cancer Prev 2010;11:1341-6.

[10] Khan NA, Teli MA, Katoch S, et al. The effect of smoking habits on different histological types of lung cancer in Kashmir. JK Science 2008;10(1):23-5.

[11] Alamoudi OS. Lung cancer at a university hospital in Saudi Arabia: a four year prospective study of clinical, pathological, radiological, bronchoscopic, and biochemical parameters. Ann Thorac Med 2010;5(1):30-6.

[12] Behera D, Balamugesh T. Indoor air pollution as a risk factor for lung cancer in women. JAPI 2005;53:190-2.

[13] Notani PN, Rao DN, Sirsat MV, et al. A study for lung cancer in relation of bidi smoking in different religious communities in Bombay. Indian $J$ Cancer 1977;14(2):115-21.

[14] Newcomb PA, Carbone PP. The health consequences of smoking cancer. Medical clinics of North America 1992;76(2):305-31.

[15] Lee JJ, Lin RL, Chen CH, et al. Clinical manifestations of bronchogenic carcinoma. Jour of the Formosan Medical Assoc 1992;91(2):146-51.

[16] Shimizu H, Preston-Martin S, Casagrande JT, et al. Epidemiological characteristics of adenocarcinoma of the lung in Los Angeles country. National Cancer Institute Monographs 1982;62:161-4.

[17] Dull WL. Needle aspiration biopsy in suspected pulmonary carcinoma. Respiration 1980;39(5):291-4.

[18] Gupta RC, Purohit SD, Sharma MP, et al. Primary bronchogenic carcinoma: clinical profile of 279 cases from mid-west Rajasthan. Indian J Chest Dis Allied Sci 1998;40(2):109-16.

[19] Khan NA, Afroz F, Lone MM, et al. Profile of lung cancer in Kashmir, India: a five-year study. The Indian Journal of Chest Diseases \& Allied Sciences 2006;48(3):18790.

[20] Gaur DS, Thapliyal NC, Kishore S, et al. Efficacy of broncho-alveolar lavage and bronchial brush cytology in diagnosing lung cancers. Journal of cytology 2007;24(2):73-4.

[21] Naseem N, Sadiq S, Nagi A, et al. A pattern of carcinoma of lung as seen in a tertiary care hospital. Biomedica 2008;24:118-23.

[22] Perng DW, Perng RP, Kuo BI, et al. The variation of cell type distribution in lung cancer: a study of 10,910 cases at a medical center in Taiwan between 1970 and 1993. Japanese Journal of Clinical Oncology 1996;26(4):229-33.

[23] Medina FM, Barrera RR, Morales JF, et al. Primary lung cancer in Mexico city: a report of 1019 cases. Lung cancer 1996;14(2-3):185-93.

[24] Lam KY, Fu KH, Wong MP, et al. Significant changes in the distribution of histologic types of lung cancer in Hong Kong. Pathology 1993;25(2):103-5. 